J Immigr Minor Health. 2016 August ; 18(4): 828-835. doi:10.1007/s10903-015-0325-7.

\title{
Suicidal Ideation and Mental Health of Bhutanese Refugees in the United States
}

\section{Trong Aoe ${ }^{1}$, Sharmila Shetty ${ }^{1}$, Teresa Sivilli ${ }^{1}$, Curtis Blanton ${ }^{1}$, Heidi Ellis ${ }^{2,3}$, Paul L. Geltman $^{3,4}$, Jennifer Cochran ${ }^{4}$, Eboni Taylor ${ }^{1}$, Emily W. Lankau ${ }^{1,5,6}$, and Barbara Lopes Cardozo ${ }^{1}$}

Trong Aoe: tfa8@cdc.gov; Sharmila Shetty: acq1@cdc.gov; Teresa Sivilli: teri.sivilli@gmail.com; Curtis Blanton: cgb9@cdc.gov; Heidi Ellis: Heidi.Ellis@childrens.harvard.edu; Paul L. Geltman: paul.geltman@state.ma.us; Jennifer Cochran: jennifer.cochran@state.ma.us; Eboni Taylor: jyo1@cdc.gov; Emily W. Lankau: emily.wheeler@alumni.rice.edu; Barbara Lopes Cardozo: bhc8@cdc.gov

${ }^{1}$ Emergency Response and Recovery Branch, Center for Global Health, Centers for Disease Control and Prevention, 1600 Clifton Road, Mailstop E-22, Atlanta, GA 30329, USA

${ }^{2}$ Boston Children's Hospital, Boston, MA, USA

${ }^{3}$ Harvard Medical School, Boston, MA, USA

${ }^{4}$ Massachusetts Department of Public Health, Boston, MA, USA

${ }^{5}$ LandCow Consulting, Athens, GA, USA

${ }^{6}$ Department of Infectious Diseases, University of Georgia, Athens, GA, USA

\section{Abstract}

Refugee agencies noticed a high number of suicides among Bhutanese refugees resettled in the United States between 2009 and 2012. We aimed to estimate prevalence of mental health conditions and identify factors associated with suicidal ideation among Bhutanese refugees. We conducted a stratified random cross-sectional survey and collected information on demographics, mental health conditions, suicidal ideation, and post-migration difficulties. Bivariate logistic regressions were performed to identify factors associated with suicidal ideation. Prevalence of mental health conditions were: depression (21\%), symptoms of anxiety (19\%), post-traumatic stress disorder $(4.5 \%)$, and suicidal ideation ( $3 \%)$, significant risk factors for suicidal ideation included: not being a provider of the family; perceiving low social support; and having symptoms of anxiety and depression. These findings suggest that Bhutanese refugees in the United States may have a higher burden of mental illness relative to the US population and may benefit from mental health screening and treatment. Refugee communities and service providers may benefit from additional suicide awareness training to identify those at highest risk.

\section{Keywords}

Bhutanese refugees; Suicide; Mental health; PTSD; Post-migration difficulties

The findings and conclusions in this report are those of the authors and do not necessarily represent the views of the Centers for Disease Control and Prevention.

Compliance with Ethical Standards

Conflict of interest On behalf of all authors, the corresponding author states that there is no conflict of interest. 


\section{Introduction}

From February 2009 to February 2012, the Office of Refugee Resettlement (ORR) of the United States Department of Health and Human Services (DHHS) reported 16 suicides among Bhutanese refugees who resettled in 10 states across the United States (US). Anecdotal information from refugee resettlement agencies in the US indicated that a number of suicides had occurred sporadically during this time among other resettled refugee populations in the US, including single refugees from Burma, Eritrea, Ethiopia and Burundi from 2007 to 2010, but not in the high numbers seen in the U.S. Bhutanese community. At the same time, health agencies in Nepali refugee camps where Bhutanese refugees reside also identified a high number of suicide attempts and suicide-related deaths. Consequently, in 2010, the International Organization for Migration (IOM) conducted an assessment of the psychological needs and suicide risk factors among Bhutanese refugees in these camps. From 2004 to 2010, IOM documented 64 suicide attempts and 67 suicides, which reflects a prevalence of 20.76/100,000. They also found a high prevalence of mental illnesses in this population and an association between suicide and both gender-based violence and family history of mental illness [1].

Although the mental health of Bhutanese refugees in Nepal has been studied previously, [27] no systematic investigation has focused on the mental health and suicide risks of Bhutanese refugees in the US. Between January 2008 and November 2014, more than 78,541 Bhutanese refugees were resettled to the US. Because this was a growing population at the time of our survey, with a previously reported high burden of mental illness, better understanding the magnitude of mental illness and risk factors for suicidal ideation among Bhutanese refugees became crucial for refugee health providers and programs in the US to help guide appropriate services, interventions, and prevention strategies. Therefore, at the request of ORR, the authors conducted a community-based cross-sectional survey with the following objectives: to better understand post-migration difficulties, coping mechanisms, and perceived social support; to assess the prevalence of suicidal ideation and symptoms of mental health conditions; and to identify factors associated with suicidal ideation in USresettled Bhutanese refugees.

\section{Methods}

\section{Study Population and Recruitment}

Since data on the prevalence of mental health conditions among the Bhutanese refugee population resettled in the US were not available, overall sample size was based on an estimated prevalence of $50 \%$. Assuming an adult population of approximately 10,000 and a design effect of 1.0 (random sample), a sample size of 370 was calculated to achieve a precision of $\pm 5 \%$ around with a $95 \%$ confidence interval. Assuming a $20 \%$ non-response rate and $20 \%$ outdated contact information rate, recruitment targeted a sample of 579 respondents.

The survey population framework was based on data obtained from the Worldwide Refugee Admissions Processing System (Bureau of Population Refugees and Migration, US 
Department of State) on Bhutanese refugees resettled in the four US states with the largest Bhutanese refugee populations among the ten states where suicides had occurred. A total of 579 Bhutanese refugees were randomly selected from seven cities where suicides occurred in the four states: Georgia (Atlanta), New York (Buffalo, Syracuse), Arizona (Phoenix, Tucson) and Texas (Dallas/Fort Worth, Houston). Bhutanese refugees aged 18 years or older who resettled in the four states from January 1, 2008 to November 17, 2011 were eligible for inclusion. Refugees were excluded from the study if they declined to consent, failed to complete the interview in English or Nepali, or relocated to another city. Purposive sampling was used to keep the enrolled sample's geographic distribution proportionate to that of the four states. Probability Proportional to Size (PPS) sampling was done in order to obtain representativeness of the population.

After no more than three contact attempts, surveys were conducted by trained interviewers in either the Nepali or English in the participant's home. Bilingual interviewers were recruited from each city and trained by research staff. Centers for Disease Control and Prevention (CDC) staff were on site to supervise and manage enrollment and data collection at all times. In each state, names of mental health professionals available for referral were provided to all participants and all interviewers were trained in how to refer a respondent who expressed suicidal ideation.

\section{Survey Instruments}

The survey instruments included content on demographics, mental health history and current symptoms, current substance use, past or current suicide attempts or ideation, and postmigration difficulties [8] and coping mechanisms [9] and have been previously described in detail [10]. The Perceived Social Support Scale was used to assess how the participant perceived his/her social supports [11] and categorized as low (0-39), moderate (40-49), or high (50-60). The Interpersonal Needs Questionnaire measured the extent to which respondents felt connected to others or like a burden to others [12]. Lastly, questions related to suicide risk, ideation, and exposure were assessed using a 19-item measure derived from the Suicidality Module of the World Mental Health Composite International Diagnostic Interview [13], the Scale for Suicidal Ideation [14], and the Disability Injury Survey, Afghanistan (CDC, unpublished, 2001). The Hopkins Symptom Checklist (HSC) was used to assess symptoms of anxiety, depression, and psychological distress over the preceding 4 weeks [15]. The total HSC score also was used to rate general psychological distress [15, 16]. The Harvard Trauma Questionnaire was used to enumerate traumatic events experienced prior to resettlement and to assess symptoms of post-traumatic stress disorders (PTSD) $[17,18]$.

Survey instruments were translated and back-translated to and from Nepali by consensus technique. Trained bilingual and bicultural interviewers contacted the potential participants, obtained informed consent, and administered the survey in the respondent's home using the respondent's preferred language (English or Nepali). Supervising study staff ensured that the interviewer and the respondent did not know each other. 


\section{Statistical Analysis}

Demographic characteristics are reported in frequencies and percentages for the total and stratified by sex. Chi squared tests with significance level of $p<0.05$ were used to detect statistical differences by gender. For continuous variables, medians and ranges were reported and the Wilcoxon ranked-sum test for differences in medians between men and women was used. Conditional logistic regression estimated crude and adjusted bivariate associations between suicidal ideation and potential risk factors.

\section{Human Subjects Protection}

This study was approved and monitored by the CDC's Institutional Review Board. Informed consent was obtained. Illiterate participants provided verbal consent.

\section{Results}

Of 579 randomly recruited, 423 (73\%) enrolled in the study. Reasons for non-participation were relocation (14\%), refusal (7\%), no contact information (2\%), not meeting eligibility criteria (2\%), and unknown (2\%). Demographics are described in Table 1. Median age was 34 years $($ range $=18-83$ ). Median household size was 5 persons (range $=1-14)$. Median number of children in the family was two, and median time in the US was 1.8 years (range = $0.2-5$ ). Age and sex distributions of the study sample statistically matched those of the 78,541 refugees who resettled in the US following Jan 1, 2008.

The overall mean for perceived social support was 34.3 (range $=10.0-48.0$ ) out of 60 total, which fell into the low social support range. We defined low social support as a score between 0 and 39, moderate social support (40-49) and high social support (50-60). Women reported slightly higher perceived social support than men (mean $=35.0$ vs. $33.6, p=0.01$ ). Illicit drug use was reported by $6(1 \%)$ of the participants. Current alcohol consumption was reported by 48 (11\%) participants (20 men vs. $3 \%$ women); however, 42 (93\%) of these individuals reported drinking only occasionally. 15 (4\%) participants reported having ever been diagnosed with a mental health condition. Of those who had been diagnosed, 4 (27\%) reported having been diagnosed with depression and 7 (47\%) with anxiety; $9(60 \%)$ had been given medication for the condition. Of the nine who were given medication, 5 (55.6\%) were currently taking medication. 33 (13\%) participants reported having family members diagnosed with a mental health condition.

Seventy-eight (19\%) participants had anxiety; 82 (21\%), depression; and 68 (17\%), psychological distress. Women consistently had higher prevalence of these three conditions compared to men $(23,26$, and 23 vs. 15,16 , and $13 \%$ respectively with $p<0.05$ for all). The overall prevalence of PTSD was $5 \%(\mathrm{n}=19)$, with no statistical difference between men $(3 \%)$ and women $(6 \%)$.

Before moving to the US, 153 (36\%) had experienced four to seven traumatic events, and $145(34 \%)$ had experienced eight or more. Most frequent trauma events included lack of nationality or citizenship (91\%); having to flee suddenly (54\%); lack of adequate food, water, or clothing (51\%); and lack of safety (50\%). Men were more likely than women to report a number of traumatic events: physical violence by government authorities (15 vs. 
$2 \%, p<0.0001$ ), torture (13 vs. $3 \%, p=0.0001$ ), police corruption ( 18 vs. $4 \%, p<0.0001$ ), and lack of freedom of movement ( 61 vs. $41 \%, p<0.0001$ ). Most common post-migration stressors (reported as "Quite a bit" or "Extremely") were language barriers (62\%), lack of choice over the future (46\%), and worries about family back home (39\%). Only $3(0.7 \%)$ participants reported a crime committed against them or their family in the US.

Thirteen survey participants (3\%) reported that they had ever thought seriously about committing suicide in their lifetime. Of these, nine had thought about it in the past year, three had ever made a plan, and one had ever made an attempt. Twenty-two (5\%) participants reported a suicide in the family, and $83(20 \%)$ knew a neighbor or a friend who had committed suicide. When participants were asked what they would do if they were seriously thinking about committing suicide (at any time), the most frequent response was to talk to a friend or a relative (26\%). This was followed by seeing a doctor (21\%) and seeing a mental health professional $(16 \%)$. Only $9(2 \%)$ said they would use a crisis hotline to seek help.

When participants were asked to identify the coping mechanism that they most likely used in stressful situations, 252 (60\%) answered "tried to solve the problem," and 218 (52\%) said "thought what needed to be done." Other common responses included "formed a plan of action in your mind" $(182,43 \%)$ and "went to a friend to help you feel better" $(139,33 \%)$.

\section{Factors Associated with Suicidal Ideation}

Compared to those who reported to be providers for their families (defined as a person whose expected role is to be financially responsible for the family, regardless of employment status), those who were not a provider had higher odds of reporting having suicidal ideation ever (adjusted odds ratio $[\mathrm{aOR}]=6.6 ; 95 \%$ confidence interval $[\mathrm{CI}]=1.4-31.9$ ).

Participants reporting symptoms of anxiety over the past 4 weeks were more likely to report a history of suicidal ideation than those who did not report anxiety $(\mathrm{aOR}=38.1 ; 95 \% \mathrm{CI}=$ 7.9-185.1) as was the case for those with symptoms of depression $(\mathrm{aOR}=11.2 ; 95 \% \mathrm{CI}=$ 2.9-42.1) and distress $(\mathrm{aOR}=15.0 ; 95 \% \mathrm{CI}=3.9-57.1)$ (Table 2).

Participants having symptoms of PTSD had higher odds of reporting a history of suicidality $(\mathrm{aOR}=9.3 ; 95 \% \mathrm{CI}=2.1-41.0)$ as was the case for those who experienced having their house or shelter burned down $(\mathrm{aOR}=3.4 ; 95 \% \mathrm{CI}=1.1-10.3)$. Those who expressed a history of suicidal ideation and those who did not reported similar numbers of traumatic events.

Family conflict $(\mathrm{aOR}=22.6 ; 95 \% \mathrm{CI}=5.5-92.6)$ and inability to find work $(\mathrm{aOR}=11.1$; $95 \% \mathrm{CI}=2.4-51.5)$ were the main post-migration difficulties associated with past suicidal ideation. Additional post-migration difficulties were associated with suicidal ideation: (1) poor access to counseling services ( $\mathrm{aOR}=7.9 ; 95 \% \mathrm{CI}=2.5-25.4)$; (2) lack of choice over the future $(\mathrm{aOR}=4.7 ; 95 \% \mathrm{CI}=1.2-17.8)$; (3) receiving little assistance from the government $(\mathrm{aOR}=3.6 ; 95 \% \mathrm{CI}=1.2-11.4)$; and lack of community structures for family disputes $(\mathrm{aOR}=4.8 ; 95 \% \mathrm{CI}=1.2-19.8)($ Table 2$)$. 
Respondents who said they wished that people would leave them alone (aOR $=14.5 ; 95 \%$ $\mathrm{CI}=3.9-52.8)$, thought about how to solve a problem $(\mathrm{aOR}=7.0 ; 95 \% \mathrm{CI}=1.5-33.1)$, and who talked to community leaders and/or elders regarding the problem $(\mathrm{aOR}=3.4 ; 95 \% \mathrm{CI}$ $=1.0-11.7)$ had higher odds of reporting a history of suicidal ideation compared to those who did not report using these as coping mechanisms.

\section{Discussion}

This study found high levels of anxiety and depression symptomatology among the randomly selected Bhutanese refugee respondents. Significant associations with suicidal ideation included not being a provider of the family; perceiving low social support; having symptoms of anxiety, depression, and psychological distress; and experiencing increased family conflict after resettlement. The study's observed $3 \%$ prevalence of a history of suicidal ideation, however, is substantially lower than the lifetime prevalence of $9.2 \%$ in a large multinational study, which included individuals from developed and as well as developing countries [19]. However, suicidal ideation is comparable to the prevalence in the United States of $3.7 \%$ [20]. It is likely that the prevalence in our study population is an underestimate since mental illness and suicide carry a strong stigma in the Bhutanese community and respondents may have been reluctant to disclose this information despite the high prevalence of mental health symptoms.

The World Health Organization estimates that approximately 800,000 people annually commit suicide, with a global annual mortality rate of 11.4 per 100,000 [21]. The rate of suicides among US-resettled Bhutanese refugee communities was 21.5 per 100,000 [22], higher than both the global rate and the US rate of 12.4 [23] but consistent with the estimated rate $(20.76 / 100,000)$ in refugee camps in Nepal [1]. Although suicide rates among Bhutanese refugees were similar before and after resettlement, associated factors varied. In the camps, risk factors for suicide included gender-based violence, living in family with multiple specific needs (as defined by the United Nations High Commissioner for Refugees), and having a family history of mental illness [1]. In the US, risk factors for suicidal ideation included not being a provider for the family; and reporting symptoms of anxiety, depression, and psychological distress.

Despite only $4 \%$ of respondents reporting a previous mental health condition, the study revealed a high prevalence of symptoms of anxiety, depression, and distress, with a significantly higher prevalence in women. Potentially, a significant but undiagnosed burden of mental illness exists in these Bhutanese communities. The prevalence of depression in the past four weeks in this Bhutanese was $21 \%$, nearly triple the $6.7 \%$ prevalence of depression among adults in the US in the past 12 months [24]. Only two people were in the US less than 90 days ( 74 and 86 days) and neither of them met the criteria for depression. It is therefore unlikely that that the symptoms of depression we found in our survey were the signs of an adjustment disorder instead of depression.

Similarly in the past 4 weeks, $19 \%$ of respondents reported symptoms of anxiety, compared to the prevalence of anxiety in the US adult population of $15 \%$ (lifetime) and $10 \%$ (past 12 months) [25]. Finally, $5 \%$ of this study's respondents met criteria for PTSD, compared to 
the lifetime prevalence of PTSD among the US population of $6.8 \%$ [23], and in the past 12 months, $3.5 \%$ [26]. Since our survey asked about symptoms in the past 4 weeks, the yearly prevalence of these symptoms in this population is likely to be higher than observed. Since the assessment in Nepal suggested emotional distress is often somaticized [1], medical clinicians working with Bhutanese should view non-specific somatic complaints as clues to underlying emotional distress.

The study findings give emphasis to the need for the development of community-based responses preventive interventions as well as for community leaders and service providers to identify at-risk individuals. The association between suicidal ideation and the coping mechanism of wishing that "people would just leave you alone" highlight the need to identify these individuals as potentially high risk, as people who socially isolate themselves are more likely to be at risk to act on suicidal thoughts [26]. About one-quarter of respondents said that they would seek help from a friend or relative if considering suicide. Thus in addition to individualized services targeting high-risk persons for suicide prevention, community-based approaches such as community support groups and social activity groups may prove helpful. In addition, the significantly higher prevalence of symptoms among women highlights the need to consider interventions such as support or social groups that specifically address women's issues and needs.

In contrast, only $2 \%$ of respondents reported they would use a suicide hotline when in crisis. This may indicate lack of awareness of hotlines and/or poor access to culturally and linguistically appropriate services and is particularly noteworthy since language barriers were associated with suicidal ideation. More innovative approaches might be needed in designing suicide prevention services that are culturally appropriate and accessible for refugee groups.

This investigation was subject to several limitations. Suicide and mental health are inherently difficult to research because they often are sensitive topics in many communities, not only the Bhutanese. Suicidal ideation was likely subject to reporting bias and increased variance due to the small sample size. Suicide attempts and self-reported mental health conditions were likely under-reported because of the sensitivity of the topic. While Bhutanese interviewers should have reduced cultural and linguistic barriers to participation, they may have introduced a reporting bias towards socially-acceptable responses. The study team tried to minimize this by ensuring that interviewers did not interview participants they knew personally and training all interviewers on how to minimize bias.

In addition, the study collected information about suicidal ideation and risk factors at the time the survey was conducted; therefore, it cannot draw conclusions about causality. Although the study used standardized instruments to collect information, the instruments were not validated for use with Bhutanese populations. Furthermore, because no structured clinical interviews were performed, the extent to which self-reported symptoms of PTSD, depression, and anxiety would match clinical diagnosis is unclear. Lastly, the results of this investigation are not necessarily generalizable to other Bhutanese populations outside of the survey area (because of the possibility of geographic clustering based on sociocultural factors that may bear on suicidality or mental health) or to other refugee populations. 
Lastly, the association between suicidal ideation and inability to find work bear relevance on the need for larger societal changes. Relevant socioeconomic structural needs in refugee resettlement like providing better employment and educational opportunities (with a focus on overcoming linguistic issues) may be appropriate for consideration at a policy level as part of a comprehensive strategy on improving mental health outcomes and suicide prevention. Such planning could benefit from involvement of all stakeholders, including service providers, community leaders and members, policy makers, and others involved in the refugee resettlement process.

\section{New Contribution to the Literature}

The unique multi-state study of the Bhutanese refugee population resettled in the United States reports prevalence of mental health conditions and risk factors associated with suicidal ideation. Significant risk factors for suicidal ideation included not being an economic provider for the family; perceiving low social support; having symptoms of anxiety, depression, and distress; and increased family conflict after resettlement. These findings suggest that Bhutanese refugees in the US may have a high burden of mental illness relative to the general US population. Mental health screening and treatment should be considered a priority. Refugee communities and service providers may benefit from additional suicide awareness training to identify those at highest risk for early intervention and prevention.

\section{Acknowledgments}

We gratefully acknowledge the following individuals and organizations for their invaluable contribution to this study: Office for Refugee Resettlement (Eskinder Negash, Marta Brenden, Makda Belay, Essey Workie); Arizona Department of Health Services (Ken Komatsu, Carrie Senseman, Markay Adams); Texas Department of State Health Services (Jessica Montour); Georgia Department of Public Health (Monica Vargas); New York State Department of Health (Eric Cleghorn; Cheryl Brown; Stephanie Anderton); Resettlement agencies and Bhutanese Community Leaders of: Atlanta, Georgia, Buffalo and Syracuse, New York, Dallas/Fort Worth and Houston, Texas, Phoenix and Tucson, Arizona; CDC Students and Fellows (Cathy Baroang, Jaya Kannan, Karren Lamay, Sonia Hegde, Colin Basler, Navit Robkin, Ashley Hagaman, Ugonna Ijeoma); Psychological Autopsy Interviewers (Markay Adams; Mike Gronostaj; Jeff McCollum; Dulces Morales; Amy Peterson; Loren Rodgers; Gigi Rose; Maria Said; Laura Vonnahme); CDC Collaborators (DGMQ/IRHMB, DGDDER/IERHB, Division of Injury Prevention-Alex Crosby, M.D., Thomas Niederkrotenthaler; Pathways to Wellness-Michael Hollifield, M.D., Boston Children's Hospital-Alisa Miller, Ph.D.).

\section{References}

1. Schininà, G.; Sharma, S.; Gorbacheva, O.; Mishra, AK. Who Am I? Assessment of psychosocial needs and suicide risk factors among Bhutanese refugees in Nepal and after the third country resettlement. International Organization for Migration. 2011. https://www.iom.int/files/live/ sites/iom/files/What-We-Do/docs/Mental-Health-Assessment-Nepal_Final_11March.pdf

2. van Ommeren M, Sharma B, Sharma GK, Komproe IH, Cardena E, de Jong JT. The Relationship between somatic and PTSD symptoms among Bhutanese refugee torture survivors: examination of comorbidity with anxiety and depression. J Trauma Stress. 2002; 15:415-21. [PubMed: 12392230]

3. Shrestha NM, Sharma B, Van Ommeren M, et al. Impact of torture on refugees displaced within the developing world—symptomatology among Bhutanese refugees in Nepal. JAMA. 1998; 280:443-8. [PubMed: 9701080]

4. Luitel NP, Jordans M, Murphy A, Roberts B, McCambridge J. Prevalence and patterns of hazardous and harmful alcohol consumption assessed using the AUDIT among Bhutanese refugees in Nepal. Alcohol. 2013; 48:349-55. 
5. Van Ommeren M, de Jong JT, Sharma B, Komproe I, Thapa SB, Cardena E. Psychiatric disorders among tortured Bhutanese refugees in Nepal. Arch Gen Psychiatry. 2001; 58:475-82. [PubMed: 11343527]

6. Van Ommeren M, Sharma B, Komproe I, et al. Trauma and loss as determinants of medically unexplained epidemic illness in a Bhutanese refugee camp. Psychol Med. 2001; 31:1259-67. [PubMed: 11681552]

7. Mills E, Singh S, Roach B, Chong S. Prevalence of mental disorders and torture among Bhutanese refugees in Nepal: a systemic review and its policy implications. Med Confl Surviv. 2008; 24:5-15. [PubMed: 18456987]

8. Laban CJ, Gernaat HB, Komproe IH, van der Tweel I, De Jong JT. Postmigration living problems and common psychiatric disorders in Iraqi asylum seekers in the Netherlands. J Nerv Ment Dis. 2005; 193:825-32. [PubMed: 16319706]

9. Amirkhan JH. A factor analytically derived measure of coping: the coping strategy indicator. J Personal Soc Psychol. 1990; 59:1066-74.

10. Ellis BH, Lankau EW, Ao T, Benson MA, Miller AB, Shetty S, Cardozo BL, Geltman PL, Cochran J. Understanding Bhutanese refugee suicide through the interpersonal-psychological theory of suicidal behavior. Am J Orthopsychiatry. 2015; 85:43-55. [PubMed: 25642653]

11. Cutrona CE. Ratings of social support by adolescents and adult informants: degree of correspondence and prediction of depressive symptoms. J Personal Soc Psychol. 1989; 57:723-30.

12. Van Orden KA, Witte TK, Cukrowicz KC, Braithwaite SR, Selby EA, Joiner TE. The interpersonal theory of suicide. Psychol Rev. 2010; 117:575-600. [PubMed: 20438238]

13. Kessler RC, Ustun TB. The world mental health (WMH) survey initiative version of the World Health Organization (WHO) composite international diagnostic interview (CIDI). Int J Methods Psychiatr Res. 2004; 13:121.

14. Beck AT, Kovacs M, Weissman A. Assessment of suicidal intention: the scale for suicide ideation. J Consult Clin Psychol. 1979; 47:343-52. [PubMed: 469082]

15. Kleijn WC, Hovens JE, Rodenburg JJ. Posttraumatic stress symptoms in refugees: assessments with the Harvard Trauma Questionnaire and the Hopkins symptom Checklist-25 in different languages. Psychol Rep. 2001; 88:527-32. [PubMed: 11351903]

16. Sandanger I, Moum T, Ingebrigtsen G, Sùrensen T, Dalgard OS, Bruusgaard D. The meaning and significance of caseness: the Hopkins Symptom Checklist-25 and the Composite International Diagnostic Interview II. Soc Psychiatr Epidemiol. 1999; 34:53-9.

17. Mollica RF, Caspi-Yavin Y, Bollini P, Truong T, Tor S, Lavelle J. The Harvard Trauma Questionnaire. Validating a cross-cultural instrument for measuring torture, trauma, and posttraumatic stress disorder in Indochinese refugees. J Nerv Ment Dis. 1992; 180:111-6. [PubMed: 1737972]

18. Mollica RF, Donelan K, Tor S, et al. The effect of trauma and confinement on functional health and mental health status of Cambodians living in Thailand-Cambodia border camps. JAMA. 1993; 270:581-6. DOI: 10.1001/jama.1993.03510050047025 [PubMed: 8331755]

19. Nock MK, Borges G, Bromet EJ, et al. Cross-national prevalence and risk factors for suicidal ideation, plans and attempts. Br J Psychiatry J Mental Sci. 2008; 192:98-105.

20. Crosby AE, Han B, Ortega L, et al. Suicidal thoughts and behaviors among adults aged $\geq 18$ Years —United States, 2008-2009. MMWR. 2011; 60(SS13):1-22. [PubMed: 22012169]

21. World Health Organization. Preventing suicide: a global imperative. 2014. http://www.who.int/ mental_health/suicide-prevention/exe_summary_english.pdf

22. Cochran J, Geltman P, Ellis H, et al. Suicide and suicidal ideation among Bhutanese refugeesUnited States, 2009-2012. MMWR. 2013; 62:533-6. [PubMed: 23820966]

23. CDC. Fatal injuries report, national and regional, 1999-2010. 2013. http://www.cdc.gov/injury/ wisqars/fatal_injury_reports.html

24. Kessler RC, Chiu WT, Demler O, Merikangas KR, Walters EE. Prevalence, severity, and comorbidity of 12-month DSM-IV disorders in the National Comorbidity Survey Replication. Arch Gen Psychiatry. 2005; 62:617-27. [PubMed: 15939839] 
25. Kessler RC, Aguilar-Gaxiola S, Alonso J, et al. The global burden of mental disorders: an update from the WHO World Mental Health (WMH) surveys. Epidemiol Psichiatr Soc. 2009; 18:23-33. [PubMed: 19378696]

26. Kessler RC, Berglund P, Demler O, Jin R, Merikangas KR, Walters EE. Lifetime prevalence and age-of-onset distributions of DSM-IV disorders in the National Comorbidity Survey Replication. Arch Gen Psychiatry. 2005; 62:593-602. [PubMed: 15939837] 


\section{Table 1}

Demographic characteristics of Bhutanese refugees participating in community-based survey, 2012

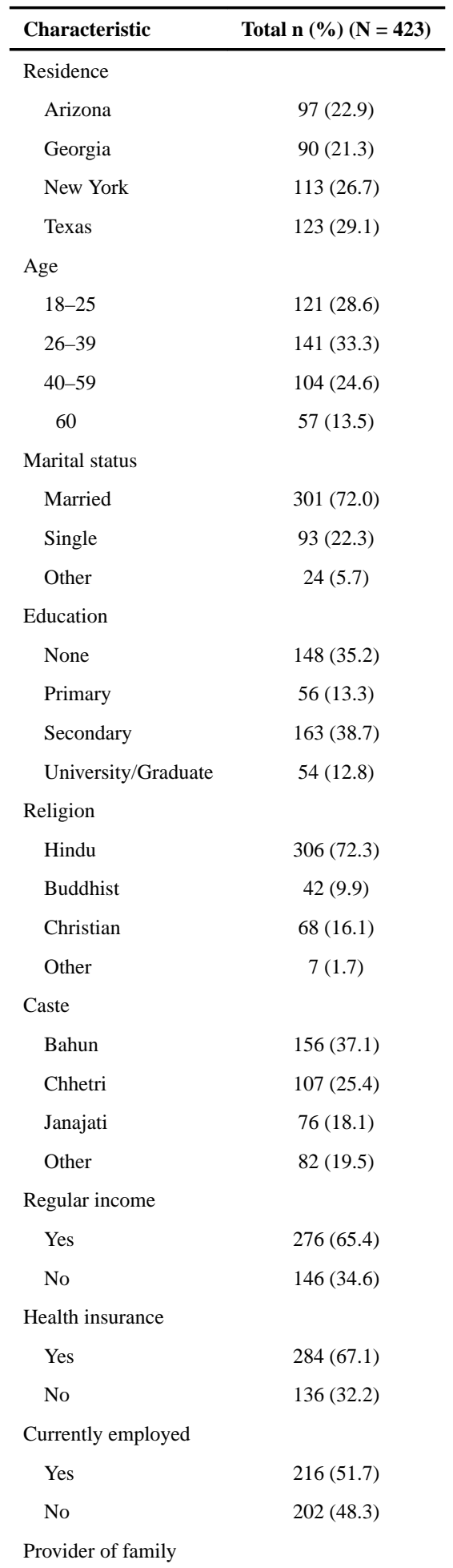




\begin{tabular}{cc}
\hline Characteristic & Total $\mathbf{n}(\boldsymbol{\%})(\mathbf{N}=\mathbf{4 2 3})$ \\
\hline Yes & $205(48.5)$ \\
No & $218(51.5)$ \\
General health & \\
Excellent & $16(3.8)$ \\
Very good & $40(9.5)$ \\
Good & $112(26.5)$ \\
Fair & $153(36.2)$ \\
Poor & $102(24.1)$ \\
\hline
\end{tabular}




\section{Table 2}

Adjusted bivariate association between characteristics of Bhutanese refugee resettled in the United States and suicidal ideation, $2012(\mathrm{~N}=423)$

\begin{tabular}{|c|c|c|c|}
\hline Characteristic & Suicidal ideation $n(\%)(n=13)$ & No suicidal ideation $n(\%)(n=404)$ & $\mathrm{aOR}^{a}(95 \% \mathrm{CI})$ \\
\hline \multicolumn{4}{|c|}{ Provider of family } \\
\hline No & $11(84.6)$ & $204(50.5)$ & \\
\hline Yes & $2(15.4)$ & $200(49.5)$ & $6.6(1.4-31.9)$ \\
\hline \multicolumn{4}{|l|}{ Anxiety $b$} \\
\hline No & $2(15.4)$ & $337(83.4)$ & \\
\hline Yes & $11(84.6)$ & $67(16.6)$ & $38.1(7.9-185.1)$ \\
\hline \multicolumn{4}{|l|}{ Depression $b$} \\
\hline No & $4(33.3)$ & $307(80.6)$ & \\
\hline Yes & $8(66.7)$ & $74(19.4)$ & $11.2(2.9-42.1)$ \\
\hline \multicolumn{4}{|l|}{ Distress $b$} \\
\hline No & $4(33.3)$ & $321(84.3)$ & \\
\hline Yes & $8(66.7)$ & $60(15.8)$ & $15.0(3.9-57.1)$ \\
\hline \multicolumn{4}{|c|}{ Post-traumatic stress disorder ${ }^{c}$} \\
\hline No & $10(76.9)$ & $388(96.0)$ & \\
\hline Yes & $3(23.1)$ & $16(3.9)$ & $9.3(2.1-41.0)$ \\
\hline \multicolumn{4}{|c|}{ Burning down of house or shelter } \\
\hline No & $6(46.2)$ & $299(74.0)$ & \\
\hline Yes & $7(53.9)$ & $105(26.0)$ & $3.4(1.1-10.3)$ \\
\hline \multicolumn{4}{|c|}{ Increased family conflict } \\
\hline No & $9(69.2)$ & $396(98.1)$ & \\
\hline Yes & $4(30.8)$ & $8(1.9)$ & $22.6(5.5-92.6)$ \\
\hline \multicolumn{4}{|c|}{ Being unable to find work } \\
\hline No & $2(15.4)$ & $259(64.1)$ & \\
\hline Yes & $11(84.6)$ & $145(35.9)$ & $11.1(2.4-51.5)$ \\
\hline \multicolumn{4}{|c|}{ Poor access to counseling services } \\
\hline No & $5(38.5)$ & $329(81.4)$ & \\
\hline Yes & $8(61.5)$ & $75(18.6)$ & $7.9(2.5-25.4)$ \\
\hline \multicolumn{4}{|c|}{ Lack of community structures for family dispute } \\
\hline No & $10(76.9)$ & $374(92.6)$ & \\
\hline Yes & $3(23.1)$ & $30(7.4)$ & $4.8(1.2-19.8)$ \\
\hline \multicolumn{4}{|c|}{ Lack of choice over future } \\
\hline No & $3(76.9)$ & $219(54.2)$ & \\
\hline Yes & $10(76.9)$ & $185(45.8)$ & $4.7(1.2-17.8)$ \\
\hline \multicolumn{4}{|c|}{ Little help from government } \\
\hline No & $5(38.5)$ & $279(69.1)$ & \\
\hline Yes & $8(61.5)$ & $125(30.9)$ & $3.6(1.2-11.4)$ \\
\hline
\end{tabular}




\begin{tabular}{lrrr}
\hline Characteristic & Suicidal ideation $\mathbf{n}(\%)(\mathbf{n}=\mathbf{1 3})$ & No suicidal ideation $\mathbf{n}(\%)(\mathbf{n}=\mathbf{4 0 4})$ & $\mathbf{a O R}^{\boldsymbol{a}}(\mathbf{9 5} \% \mathbf{C I})$ \\
\hline \multicolumn{2}{l}{ Wished that people would just leave you alone } & & \\
No & $8(61.5)$ & $381(94.3)$ & \\
Yes & $5(38.5)$ & $23(5.7)$ & \\
"Thought what needed to be done" & & \\
No & $2(15.4)$ & $199(49.3)$ & $7.0(1.5-33.1)$ \\
Yes & $11(84.6)$ & $205(50.7)$ & \\
Talked with community leaders and/or elders & & \\
No & $9(69.2)$ & $355(87.9)$ & $3.4(1.0-11.7)$ \\
Yes & $4(30.8)$ & $49(12.1)$ & \\
\hline
\end{tabular}

${ }_{\text {aOR }}=$ adjusted Odds Ratio (adjusted for state of residence, age, and sex)

$b_{\text {Based on Hopkins Symptom Checklist }}$

$c_{\text {Based on Harvard Trauma Questionnaire }}$ 